\title{
ENTREVISTA CON AIMEE, DIRECTORA JEFE DE TRADUCTORES SIN FRONTERAS (TWB)
}

\author{
Carmen Valero-Garcés \\ (1) $\mathbf{G} \mathrm{R}^{\mathrm{G}} \mathbf{O}$ \\ Universidad de Alcalá \\ carmen.valero@uah.es
}

\begin{tabular}{|l|l|}
\hline & $\begin{array}{l}\text { Aimee no era consciente de que rompía los esquemas hasta que se } \\
\text { convirtió en Directora Ejecutiva de Traductores Sin Fronteras } \\
\text { (TWB). Durante más de 25 años, ha trabajado en contextos } \\
\text { humanitarios y de desarrollo en cuatro continentes para agencias de } \\
\text { la Unión Europea y ONG como Oxfam y Save the Children par } \\
\text { asegurar que los más vulnerables tienen acceso a sus derechos. } \\
\text { Traductores Sin Fronteras constituye un nexo fundamental desde el } \\
\text { que se puede cambiar el mundo, uniéndose a otros para garantizar } \\
\text { que los más marginados puedan acceder a la información, } \\
\text { comprenderla y actuar en consecuencia. Queremos llevar las } \\
\text { lenguas al mundo digitalizado, dejando a un lado las } \\
\text { comunicaciones textuales en favor del discurso y la comunicación } \\
\text { oral. }\end{array}$ \\
\hline
\end{tabular}

\section{C.V.G. ¿Qué es TWB? ¿Cuándo y por qué se fundó?}

Fue fundada originalmente en 1993 en Francia como Traducteurs sans Frontières por Lori Thicke y Ros Smith-Thomas para vincular a los traductores del mundo con organizaciones sin ánimo de lucro reconocidas que se dedican a la salud, la nutrición y la educación. TWB es una organización estadounidense sin ánimo de lucro que tiene por objeto acabar con las lagunas lingüísticas que obstaculizan los esfuerzos humanitarios y de desarrollo internacional en todo el mundo. TWB reconoce que la eficacia de cualquier programa de ayuda depende de la entrega de información en el idioma de la población afectada. Al contar con una red mundial de traductores profesionales, TWB ayuda a las organizaciones sin ánimo de lucro a superar las barreras de comunicación, aumentando el acceso a la información y los servicios básicos y fomentando al mismo tiempo un clima de comprensión, respeto y dignidad en tiempos de gran necesidad. Nuestro objetivo es un mundo donde el conocimiento no conoce las barreras del lenguaje. 
C.V.G. Cuéntanos algo sobre ti. ¿Cómo surgió tu interés por la traducción y la interpretación? ¿Cómo te convertiste en Directora Ejecutiva de TWB?

He trabajado en la ayuda humanitaria durante los últimos 25 años en más de 20 países. Aunque hablo varios idiomas, necesitaba constantemente que otros me tradujeran o interpretaran. A veces, estos traductores o intérpretes eran maestros en pequeñas aldeas. Muchos hablaban bien inglés, pero ninguno estaba capacitado para ser intérprete o traductor. Algunas de las personas con las que trabajé que eran de los países en los que trabajaba también traducían o interpretaban. A menudo me encontré "educándolos" en lo que se debe y no se debe hacer en la interpretación. Y nunca estuve segura de la precisión de las traducciones e interpretaciones.

Cuando me fui de Sudán del Sur en 2015, después de haber trabajado en varias guerras civiles brutales y en desastres naturales devastadores, quería hacer algo más que ayudar dar o asistencia técnica. La gente de esos países realmente necesitaba oportunidades e información. Necesitaban poder comunicarse y obtener la información que deseaban y no lo que los organismos de ayuda creían que necesitaban. Cuando me entré del puesto en TWB, vi el potencial que la organización podía tener a la hora de facilitar a las personas la información que necesitaban y deseaban, cuando la necesitaban y la deseaban, en un idioma y un formato que entendieran. Así que me presenté para el puesto y me contrataron. Es el mejor trabajo que he tenido.

\section{C.V.G. Hoy en día, ¿cuánta gente colabora con TWB y en cuántas lenguas se manejan?}

Bueno, esa pregunta es complicada. El número de idiomas es superior a 200, pero contar idiomas no es una ciencia exacta. La diferencia entre un idioma y un dialecto no está bien definida.

En cuanto al número de personas, decimos que la comunidad de TWB incluye más de 30.000 lingüistas. El número de personas que han traducido para la organización es en realidad mucho mayor - y varía. Los traductores pueden tener tiempo para asumir un trabajo en mayo, pero no en abril o junio. 30.000 es el número aproximado de personas que se ofrecen como voluntarios en un año. Y siempre necesitamos más - en todas las combinaciones de idiomas.

C.V.G. TWB actúa en situaciones de mucho peligro o situaciones de emergencia. ¿Hay líneas de actuación específicas dentro de las que la organización actúe? ¿Guerras, conflictos raciales, religiosos, de género...? ¿Cómo decide la organización actuar en cada situación?

Sí, normalmente respondemos a crisis, pero hablaremos de eso más adelante. Sin embargo, creo que es importante reconocer que la gente todos los días necesita información que pueda entender. La mayor parte de los 20 millones de palabras que se traducen todos los años son para organizaciones que no responden a situaciones de crisis, pero que están ayudando cada día a la gente. Por ejemplo, desde TWB trabajamos con Free Wheelchair Mission, una organización que proporciona sillas de ruedas a personas necesitadas. Trabajan en todo el mundo y llegan a comunidades remotas. Traducimos información sobre los cuidados y mantenimiento de estas sillas de ruedas, y esto es muy importante porque puede que en dichas comunidades haya gente que no ha visto una silla de ruedas en toda su vida o gente que les pueda ayudar a repararlas.

También trabajamos con SmileTrain, una organización que hace cirugías de labio leporino. Traducimos para los niños y sus familias toda la información sobre el proceso de la cirugía y la recuperación.

TWB colabora con unas 150 organizaciones y trabaja por todo el mundo con más de 200 idiomas. 


\section{C.V.G. Cuando TWB decide intervenir o desarrollar una campaña de traducción, ¿cuáles son los protocolos que seguís?}

En general, intervenimos cuando la comunicación entre los proveedores de la ayuda y las personas necesitadas se ve obstaculizada, normalmente a causa del idioma.

Si es debido a una crisis, primero preguntamos si podemos contribuir a labores que ya se estén desarrollando. No tiene sentido dar un servicio que nadie va a utilizar.

Lo siguiente es dar con la lengua o lenguas que se hablan en la zona afectada. Puede parecer algo nimio, pero resulta especialmente complicado. No en todo el mundo existen recursos fiables que nos proporcionen esta información. Algunos países cuentan con censos u otra información que pueda ser de utilidad, pero no está del todo definido. TWB tiene un proyecto dedicado tan solo a la cartografía del leguaje.

Puede que sorprenda el hecho de que la lengua no se haya tenido en consideración dentro de las respuestas humanitarias, incluso en Reino Unido y Estados Unidos a penas se contempla. Nosotros hemos cartografiado, por ejemplo, las lenguas habladas en el oeste de Estados Unidos para informar a los servicios de emergencia sobre los idiomas que se necesitan.

Si consideramos que nuestra ayuda es necesaria, entonces lo primero que hacemos normalmente es cartografiar la lengua y trabajar con organizaciones de recolección de datos para aumentar nuestro conocimiento sobre la lengua en cuestión.

Después hacemos un llamamiento a traductores a nivel mundial. Normalmente, nuestros principales colaboradores empezarán a pedir traducciones rápidamente y a otros habrá que convencerles de que la lengua está planteando un problema. Si decidimos que es necesario tener a equipos en el país en cuestión, puede que también enviamos a uno o dos de nuestros trabajadores humanitarios a esa zona.

Solemos hacer una rápida investigación sobre la lengua y los problemas de comunicación. TWB ha llevado a cabo trabajos pioneros en cuanto a las diferencias entre la Rohinyá y la Chittagoniana, sobre cuestiones de idioma en la respuesta al Ebola en la parte oriental de la República Democrática del Congo, y sobre cómo el idioma puede contribuir para los esfuerzos humanitarios en Mozambique. Basándonos en este trabajo, comenzamos a trabajar con lingüistas locales y globales y a defender la importancia del lenguaje.

Mientras hacemos esto, empezamos a traducir información, crear glosarios y a formar a intérpretes de campo. También comenzamos a entender mejor el contexto del trabajo de traducción - son lenguas escritas o no, cómo prefieren los usuarios recibir y dar la información, cuáles son las fuentes en las que más confían, están los teléfonos al alcance de hombres y mujeres de manera equitativa, cuáles son los niveles de alfabetización, cómo entienden las personas los signos - con otros, trabajamos rápidamente para escuchar a las personas y asegurarnos de que obtengan la información que desean de una manera que les sea útil. Recientemente hemos empezado a elaborar carteles localizados, a hacer más subtitulación de vídeos y a trabajar con las emisoras de radio para garantizar la difusión de la información.

Y, si profundizamos más aún, transcribimos y traducimos los comentarios de la gente, desarrollando herramientas para que las personas puedan hacer oír sus necesidades y preocupaciones de manera efectiva e innovadoras tecnologías del lenguaje para escuchar de manera consciente a la gente, ya sea con sistemas básicos de reconocimiento de voz o chatbots con los que se puedan hacer preguntas y obtener respuestas.

Hemos respondido a muchas, muchas crisis, como el terremoto de Nepal, el brote de Ebola en África occidental y los tres brotes en la República Democrática del Congo, actuamos en Grecia, en Bangladesh, en Haití y hemos respondido a muchos incendios, inundaciones y terremotos. Siempre hay gente que necesita información en su idioma. Recientemente, hemos empezado a apoyar a las organizaciones que responden a los refugiados de Tigray. 
C.V.G. ¿Cómo ha afectado la pandemia de la COVID-19 a TWB? ¿Qué medidas estáis tomando para ayudar a las lenguas minoritarias?

TWB siempre ha sido una organización descentralizada. Siempre trabajamos desde casa, por lo que la COVID-19 no ha tenido mucho impacto sobre nuestro trabajo. Nuestros equipos de Nigeria, Bangladés y la República del Congo tuvieron que reducir la formación de manera presencial, pero, como siempre hemos estado dispersos, ellos ya tenían los recursos necesarios para empezar el trabajo de manera remota por su cuenta.

Nuestra respuesta a la pandemia de la COVID-19 ha sido multifacética. Los dos grandes ejes han sido nuestro glosario para COVID-19, actualmente disponible en 50 lenguas, y el proyecto TICO-19 (Iniciativa para Traducción de la COVID-19, por sus siglas en inglés), donde lideramos un consorcio para desarrollar documentos específicos sobre la COVID en 30 lenguas. Este consorcio incluía a grandes compañías tecnológicas y muchos grandes proveedores de servicios de idiomas y universidades.

C.V.G. ¿Colaboran los gobiernos y las instituciones privadas o públicas con TWB cuando se las necesita? ¿Cómo lo hacen?

Sí. Trabajamos muy de cerca con organizaciones no gubernamentales mayoritariamente, incluyendo a algunas de las más importantes como UNICEF, Save the Children, World Vision y Oxfam.

También colaboramos con gobiernos. Por ejemplo, estamos apoyando al Ministerio de Salud de la República Democrática del Congo con el primer chatbot multilingüe que utiliza la comprensión del lenguaje natural en suajili y lingala.

C.V.G. Volviendo a la traducción y los traductores, ¿cómo puede un traductor ser miembro o colaborar con TWB? ¿Cuáles son los requisitos?

¡Solo tienes que registrarte! Puedes ser voluntario de TWB si tienes fluidez en al menos una lengua distinta a tu lengua materna. Hay proyectos muy atractivos que se ajustan a todas las preferencias, tanto si te interesa la traducción médica como traducir para la respuesta a distintas crisis. Animamos sobre todo a los traductores profesionales a que participen.

C.V.G. Teniendo en cuenta que TWB también traduce hacia lenguas de menor difusión cuando en general no hay formación disponible, ¿qué perfil suelen tener los traductores/intérpretes que trabajan con estas lenguas minoritarias? ¿Soluciones ad hoc? ¿Traductores o intérpretes sin formación? ¿Hombres, mujeres?

En casi todas partes hay gente que es multilingüe. Hacemos mucho trabajo de capacitación y entrenamiento, particularmente en herramientas de traducción asistida para la gente que no las ha utilizado nunca.

C.V.G. ¿Y qué hay de la evaluación de calidad de las traducciones? ¿Cómo se evalúan, con qué criterio?

Tenemos un proceso de revisión. En general, utilizamos algunas herramientas de control de calidad y el Dynamic Quality Framework (DQF) de Taus.

C.V.G EI tema de este número de FITISPOs IJ (vol 8, 2021) es el factor humano. Sin embargo, considerando la influencia de la traducción automática y la inteligencia artificial en la industria de la traducción, ¿qué impacto está teniendo en los traductores y en su trabajo? ¿Cómo afecta a las lenguas mayoritarias y a las minoritarias? 
TWB está desarrollando mejores herramientas para los hablantes (y traductores) de lenguas marginadas. Ahora mismo no hay muchas, y tampoco es que haya muchos traductores. Pero sí que hay mucha demanda de estas lenguas.

TWB crea conciencia sobre la importancia de la información en la lengua correcta, apoyamos a las organizaciones para asegurar que la información fundamental se comunique en la lengua que la gente utiliza. Y, para ello, formamos a traductores e intérpretes y desarrollamos herramientas lingüísticas.

\section{C.V.G ¿Dirías que el inglés se está convirtiendo en una lengua franca? ¿Cuáles son las principales lenguas de uso?}

En muchos de los lugares donde trabaja TWB, la lengua franca no es precisamente el inglés, sino por ejemplo el suajili, el hausa o el bengalí. Nuestras investigaciones han concluido en que aquellos que tienen menos posibilidad de hablar la lengua franca son precisamente los más vulnerables y necesitados de información: mujeres, niños, personas mayores y personas con discapacidad.

\section{C.V.G ¿En qué países tiene mayor presencia TWB?}

Ahora mismo, tenemos oficinas fijas en Nigeria y Bangladés. TWB también tiene unas enormes comunidades lingüísticas en francés, español, árabe, suajili y muchas otras lenguas. Tenemos un increíble programa llamado "Socios Lingüistas", en el que designamos a miembros voluntarios de la comunidad para que apoyen las actividades de compromiso con la comunidad, así como el desarrollo de recursos lingüísticos clave como guías de estilo y terminología y de garantía de calidad. Recientemente nos hemos embarcado en nuestro nuevo programa "Socios Lingüistas de amárico", además de los socios lingüistas para francés, español, somalí y algunos cuantos idiomas más. Además, pronto esperamos incluir en plantilla a socios para los idiomas oromo, hindi y el pastún.

\section{C.V.G ¿Podrías contarnos algún caso concreto de alguna situación que te haya marcado especialmente?}

¡Hay muchas! Cuando nos enseñaron una herramienta lingüística, una persona en Nigeria nos dijo que no sabía que si lengua era tan importante como para aparecer en un ordenador.

De manera personal, el impacto que el trabajo de TWB tiene en la gente nunca para de asombrarme. Como mencionaba, yo he estado trabajando por todo el mundo durante más de 25 años y es la primera vez que la gente, tanto en pequeños pueblos como en reuniones de la ONU, me dice lo mucho que aprecia nuestra labor. Me cuentan que TWB ayuda de maneras que otras organizaciones no lo hacen, poniendo sus idiomas y culturas en el foco. Les enorgullece que sus lenguas sean "suficientemente importantes", y dicen que desde TWB quieren de verdad escucharlos y entenderles porque respetamos sus lenguas y les pedimos que se expresen en sus lenguas maternas, ya que es la manera más cómoda para ellos. No les pedimos que entiendan nuestra lengua o nuestras maneras de comportarnos. Nunca se me había dado la situación de que gente que no me conoce me quiera dar las gracias por lo que TWB hace.

\section{C.V.G ¿Ha recibido TWB algún tipo de reconocimiento? ¿Existe algún tipo de proceso en su reconocimiento?}

Hemos tenido mucho reconocimiento. Gracias a nuestra comunidad global de lingüistas, el trabajo de TWB tiene mucho reconocimiento. Hemos ganado premios a la innovación y hay publicados muchos, muchos artículos sobre nuestro trabajo. Nuestro trabajo ha sido alabado en The Economist, Forbes, Voice of America, WIRED y muchos otros medios. 
TWB tiene un estatus consultivo dentro de la ONU. También estamos registrados como una organización sin ánimo de lucro en los Estados Unidos y organización caritativa en Irlanda.

\section{C.V.G ¿Alguna recomendación para los académicos interesados en la formación e investigación en esta área? ¿Y para los profesionales?}

Si hay académicos interesados en la investigación aplicada, que se pongan en contacto con nosotros. TWB tiene un pequeño pero potente equipo de investigación. Ahora mismo estamos buscando financiación para llevar a cabo, de manera muy general, una investigación sobre la lengua y los cambios de conducta y la lengua y la confianza; planteando cuestiones como si la información en la lengua y formato correcto ayuda a la gente a entender mejor los beneficios y riesgos de la vacuna de la COVID, por ejemplo, o si es más probable que ciertas comunidades confíen más en el personal sanitario si estos utilizan la lengua local.

\section{Date of reception/Fecha de recepción: 25/01/2021 \\ Date of acceptance/Fecha de aceptación: 31/01/2021}

How to cite this article?/ ¿Cómo citar este artículo?

Valero-Garcés, C. (2021). Entrevista con Aimee, Directora Jefe de Traductores sin Fronteras $\begin{array}{llll}\text { (TWB). } & \text { FITISPos-International Journal, } & \text { 8(1), } & \text { 160-165. }\end{array}$ https://doi.org/10.37536/FITISPos-IJ.2021.8.1.296 